\title{
Rhetorical Move Analysis in Students' Abstracts Across Degrees
}

\author{
Fanny Putri, Budi Hermawan*, Rd. Dian Muniroh \\ Department Pendidikan Bahasa Inggris, Universitas Pendidikan Indonesia \\ *Corresponding author. Email: budihermawan@upi.edu
}

\begin{abstract}
Abstract section of a thesis represents the whole text. It is the first thing that the readers will read and decides whether the readers will read the text as a whole or not. As a summary of the whole text, it is comprehensible that in writing abstracts, authors may put a lot of information compactly. Moreover, it is important to ensure that the abstract section is well delivered. Move analysis of an abstract can help authors to determine whether the abstracts accomplish necessary rhetorical actions. However, analysis of rhetorical moves of abstracts written in two languages is still scarce. Therefore, this study aims to investigate rhetorical moves patterns realized in abstracts of theses and dissertations in Indonesian and their translations in English. Hyland's (2000) five-move analysis model was used to analyze rhetorical moves patterns of 60 thesis and dissertation abstracts in social science taken from a university's online repository. This study reaches a conclusion that differences in education level may affect move and step realization in thesis or dissertation abstracts. From that point, authors should start to also include other moves such as introduction, purpose, and conclusion in their abstracts.
\end{abstract}

Keywords: Abstracts, dissertation, rhetorical moves analysis, thesis

\section{INTRODUCTION}

In their final year, students are obligated to conduct a final research project, then report it in a form of undergraduate theses, graduate theses, or dissertations to show their credibility. In their final writings, the abstract plays an important role because it is the first thing that the readers will read and serves as the base of readers' decision whether to continue read or not. However, formulating an abstract is often regarded as difficult due to the diversity of the abstract template (Kurniawan, Lubis, Suherdi, \& Danuwijaya, 2019).

The function of an abstract is to persuade readers that the full text is worth reading (Hyland, 2000). Move analysis is a method in analyzing the rhetorical moves of a written or spoken discourse by examining the linguistic realizations of each move (Kurniawan et al., 2019). Thus, move analysis of an abstract can help authors to determine whether his/her abstracts accomplish necessary rhetorical actions. Based on Swales' (1990) genre theory, move analysis focuses on communicative purposes of abstracts, realized through Move and Step.
Hyland (2000) proposed the five-move analysis to identify the features that distinguish abstracts as a recognizable genre. Those moves or communicative categories are Introduction (Move 1), Purpose (Move 2), Method (Move 3), Product (Move 4), and Conclusion (Move 5), each move has and performs different communicative function. Move 1 - established context of the study, Move 2-indicates purposes of the study, Move 3-provides information on the method of research, Move-states the main findings of the research, and Move 5-interprets result or gives wider implications. Hyland's framework is regarded as a more systematic system and is very common to use in academic contexts.

Studies on rhetorical move analysis have been conducted by different researchers. Move analyses of research article abstracts in various languages have been conducted several times. Tankó (2017) analyzed rhetorical moves convention and linguistics features English literature research article abstracts using Swales' model. The study revealed that literature research article abstracts have four stable moves, whose functions are to present the background, purpose, methodology, and outcomes of the research. El-Dakhs 
(2020) examined the differences in rhetorical patterns and interactional features between Arabic and English research article abstract. This study found that English and Arabic abstract emphasize different rhetorical move organization, it can be seen through the manifested move in the abstracts.

Comparison of Rhetorical Move pattern in international and national journal article abstracts also have been conducted. Using Hyland's analysis model, Tamela (2020) points at move structure pattern on research article abstracts in SCOPUS indexed journals. Another study on the rhetorical organization of abstracts from Scopus-indexed journals had been conducted by Kurniawan et al. (2019). This study revealed that journal quartile does not necessarily affect the manifestation of moves and steps.

Moreover, Indonesian researchers also had researched on rhetorical move analysis of abstracts. Male (2018) conducted a study that assesses EFL students' abstracts rhetorical convention. The results of this study found that the majority of students' abstracts were in line with Bhatia's findings. On the other hand, Gustina (2020) analyzed rhetorical move pattern and linguistics features of research article abstracts using Hyland's model. Based on the analysis, the results showed similarities and differences regarding the realization of moves, steps, and linguistic features.

Studies on rhetorical convention of undergraduate students' abstract have been conducted, however, studies which compare rhetorical move pattern of abstracts written by students across degree are still scarce. Thus, this study aims to do a genre-based comparative study on Indonesian and English abstracts of undergraduate (S1), graduate (S2), and postgraduate (S3) students' thesis or dissertation in the social science field. Social science field is chosen considering that it seems to be harder for Indonesian students in social sciences and humanities than for those in other fields of discipline to writing in English (Arono \& Arsyad, 2019).

In order to obtain relevant information, this study is driven by the following question.

RQ 1: How is the rhetorical move patterns of the Indonesian English abstracts realized across education levels?

RQ 2: How is the step pattern of the Indonesian English abstracts realized across education levels?

\section{METHOD}

This section contains explanation of how the study is conducted. It deals with the design of the research, the source of the data, and the process of collecting the data following by the process of analyzing the data.

\subsection{Research Design}

This study was designed as a qualitative comparative study. In this study, the researchers used Hyland (2000) model of Five-Move Analysis to analyze the data and then compare the rhetorical move pattern used in abstracts across degrees in the social science field both in Bahasa Indonesia and English.

\subsection{Data Sources}

First, the researchers determined the subject field and year range for data that will be analyzed. Second, researchers collected 30 Indonesian and 30 translation versions of each qualified abstract from online UPI repository. Afterward, researchers copied the whole text of each abstract from the online repository page and saved it in a word file format to be analyzed.

\subsection{Data Collection}

Table 1. Hyland Five-Move Analysis Model

\begin{tabular}{|c|c|c|}
\hline Move & Step & Description \\
\hline Introduction & 1 & Arguing for topic significance \\
\hline \multirow[t]{3}{*}{ (I) } & 2 & Making topic generalization \\
\hline & 3 & Defining the key term(s) \\
\hline & 4 & Identifying gap \\
\hline Purpose $(\mathrm{P})$ & 1 & $\begin{array}{l}\text { Stating general and/or specific } \\
\text { purpose of the research } \\
\text { including the hypothesis }\end{array}$ \\
\hline \multirow[t]{3}{*}{ Method (M) } & 1 & $\begin{array}{l}\text { Describing participants/data } \\
\text { sources }\end{array}$ \\
\hline & 2 & Describing instrument(s) \\
\hline & 3 & $\begin{array}{l}\text { Describing procedure and } \\
\text { context }\end{array}$ \\
\hline Product $(\mathrm{Pr})$ & 1 & $\begin{array}{l}\text { Describing the main specific } \\
\text { findings of the research }\end{array}$ \\
\hline \multirow{4}{*}{$\begin{array}{l}\text { Conclusion } \\
\text { (C) }\end{array}$} & 1 & Deducing conclusion \\
\hline & 2 & $\begin{array}{l}\text { Evaluating the significance of } \\
\text { the research }\end{array}$ \\
\hline & 3 & Stating limitation \\
\hline & 4 & $\begin{array}{l}\text { Presenting recommendation or } \\
\text { implication }\end{array}$ \\
\hline
\end{tabular}

Online meetings were conducted before analyzing the data to discuss and synchronize researchers' understanding of abstract, move analysis, and frameworks. The first meeting was done to determine the research timeline. The second meeting session was done to synchronize researchers' understanding of the concept of move analysis using Hyland's (2000) fivemove analysis model. The third discussion session was done to discuss the preliminary analysis result of six abstracts. Some feedback was given directly to the analysis. Afterward, the researcher analyzed all of the sixty abstracts. The five-move analysis model can be seen in table 1 . 


\subsection{Data Analysis}

Sentences were the unit of analysis. The process started with breaking down each abstract into sentences. The sentences were moved into a table, consisting of five columns: number, sentence, move, step, and verb. First, researchers identify the main verb of each sentence. Afterward, the sentences were labeled according to their corresponding move. All moves were categorized into steps. Once the analysis was finished, the results from undergraduate, graduate, and postgraduate abstracts both in Indonesia and English were compiled, tabulated, then compared to obtain the conclusion. To acquire the conclusion, first, the researchers examined the whole move and step realization pattern of the whole data. Afterward, the researchers also examined the analysis results of each education level abstracts both in English and in Indonesia separately to find the differences of rhetorical move preferences among the three degrees.

\section{FINDINGS AND DISCUSSION}

This study revealed that all the moves were manifested in the abstracts. Regarding occurrences of the move, the result of this study revealed that a total of 565 moves were used in the data. Specifically, 284 moves were found in the Indonesian version of the abstracts, meanwhile in the English translation version were found 281 moves. In this study, Move 3 (Method) was found as the most frequent move with a total of 171 data across the education levels.

Furthermore, these sub-sections aim to describe the rhetorical pattern of Indonesian English abstracts from the three education levels. These sections present the salience of the moves and step found in the abstracts. The term 'salience' refers to the number of abstracts manifesting a move or step (Kurniawan et al., 2019). First, the move pattern will be explained, the step pattern will be explained afterward.

\subsection{Rhetorical Move in Abstracts across Degree}

The analysis results showed that all abstracts exemplified five-move convention: Move 1Introduction, Move 2-Purpose, Move 3-Method, Move 4-Product, and Move 5-Conclusion. Table 2 displays the percentage of salience for each move in Indonesia and English abstracts across the three degrees as seen in table 2.
Table 2. Move Salience in Indonesian English Abstracts across Degree

\begin{tabular}{ccccccc}
\hline Move & \multicolumn{3}{c}{ Indonesian } & \multicolumn{3}{c}{ English } \\
\cline { 2 - 7 } (M) & S1 & S2 & S3 & S1 & S2 & S3 \\
\hline M1 & $80 \%$ & $90 \%$ & $100 \%$ & $70 \%$ & $90 \%$ & $100 \%$ \\
M2 & $90 \%$ & $100 \%$ & $80 \%$ & $90 \%$ & $90 \%$ & $80 \%$ \\
M3 & $100 \%$ & $100 \%$ & $100 \%$ & $100 \%$ & $100 \%$ & $100 \%$ \\
M4 & $100 \%$ & $100 \%$ & $100 \%$ & $100 \%$ & $100 \%$ & $100 \%$ \\
M5 & $40 \%$ & $10 \%$ & $70 \%$ & $40 \%$ & $10 \%$ & $80 \%$ \\
\hline
\end{tabular}

\subsubsection{Move 1}

For the undergraduate level, this move occurred $80 \%$ in Indonesian version and 70\% in English version of abstracts. Whereas for graduate and postgraduate levels, Move 1 occurred $90 \%$ and $100 \%$ respectively both in Indonesian and English version of abstracts. This move was manifested to convey several communicative purposes, such as arguing for topic significance, making topic generalizations, defining the key term(s), and identifying gap.

\subsubsection{Move 2}

Move 2 was included in abstracts to state the purpose of the study or specifically the general and/or specific purpose of the research including the hypothesis. This move occurred in a high percentage of each education level both in Indonesian and English versions. For the undergraduate level, this move occurred $90 \%$ both in Indonesian and English versions. Similarly for postgraduate students, both in Indonesia and English versions of abstracts, this move occurred $80 \%$. Meanwhile, for postgraduate levels, Move 2 occurred $100 \%$ in Indonesian abstracts, but only $90 \%$ in the English version.

\subsubsection{Move 2}

As it was considered obligatory, Move 3 occurred $100 \%$ in each level of education, both in Indonesian and in English. Move 3 expressed the methodology aspects of the study, including describing participants/data sources, describing instrument(s), and describing procedure and context.

\subsubsection{Move 4}

Likewise, this Move was also considered as obligatory as it occurred $100 \%$ in abstracts from all levels of education, both in English and Indonesian versions. This Move manifested in abstracts to describing the main specific finding of the research. 


\subsubsection{Move 5}

Move 5 included information about the conclusion of the research, including deducing conclusion, evaluating the significance of the research, stating limitation, and also presenting recommendation or implication. This move was considered optional in undergraduate and graduate levels as students from these two levels of education did not considerably put great attention in Move 5. At the graduate level, this Move only occurred $10 \%$ both in Indonesia and English version. Moreover, at the undergraduate level, it also appeared below $50 \%$, with only $40 \%$ both for Indonesia and English version. However, this Move was considered obligatory at the postgraduate level, since it occurred $70 \%$ and $80 \%$ in Indonesian and English versions respectively.

These findings demonstrate that students, regardless of the difference in education level, include all the fivemove conventions in their thesis or dissertation abstracts. This is in line with previous research about students' thesis (Gustina 2020; Male 2018). Move 3 and 4 were the most manifested moves in the abstracts across education level, it is in contrast to Li's (2020) finding that Move 3 and 4 have relatively low occurrence in Chinese abstracts. Furthermore, some minor gap of move realization between Indonesian and English is identified, even though this study used parallel abstracts. It may indicate that there is a loss or gain of information in the Indonesian and English versions of abstracts.

The differences of move realization across education level could be identified by a slight gap of Move 5 percentage among the three levels. Meanwhile, the rest of the four moves percentage occurred with a quite

stable and similar percentage, this finding agrees with Tankó (2017) who found that abstracts have four stable moves which functions are to present the background, purpose, methodology, and outcomes of research. The percentage of Move 5 got a quite noticeable gap. This Move is considered obligatory in postgraduate levels, but are rarely found in undergraduate and graduate levels. This is in line with Gustina (2020) who found that undergraduate students tend to omit Move 5 in their abstracts. Besides, there might be a tendency for the writers of undergraduate theses not to be selective in their use of the moves to best promote their papers (Male 2018).

\subsection{Rhetorical Step in Abstracts across Degree}

The analysis result revealed that each step of the rhetorical move was manifested in the abstracts from the three education levels.
As seen in table 3, the research found a total of 610 . 303 steps were manifested in Indonesian version, meanwhile, the rest 307 steps were manifested in English version of the abstracts. Table 3 displays the percentage of salience for each step in Indonesia and English abstracts across education levels.

Table 3. Step Salience in Indonesian English Abstracts across Degree

\begin{tabular}{|c|c|c|c|c|c|c|c|}
\hline \multirow{2}{*}{$\begin{array}{l}\text { Move } \\
\text { (M) }\end{array}$} & \multirow{2}{*}{ Step } & \multicolumn{3}{|c|}{ Indonesian } & \multicolumn{3}{|c|}{ English } \\
\hline & & S1 & S2 & S3 & S1 & S2 & S3 \\
\hline \multirow[t]{4}{*}{ M1 } & 1 & $50 \%$ & $60 \%$ & $80 \%$ & $50 \%$ & $60 \%$ & $70 \%$ \\
\hline & 2 & $70 \%$ & $70 \%$ & $40 \%$ & $60 \%$ & $70 \%$ & $50 \%$ \\
\hline & 3 & $0 \%$ & $10 \%$ & $10 \%$ & $10 \%$ & $10 \%$ & $10 \%$ \\
\hline & 4 & $0 \%$ & $0 \%$ & $10 \%$ & $10 \%$ & $0 \%$ & $10 \%$ \\
\hline M2 & & & & N/A & & & \\
\hline \multirow[t]{3}{*}{ M3 } & 1 & $60 \%$ & $80 \%$ & $80 \%$ & $70 \%$ & $80 \%$ & $80 \%$ \\
\hline & 2 & $80 \%$ & $80 \%$ & $70 \%$ & $60 \%$ & $70 \%$ & $60 \%$ \\
\hline & 3 & $100 \%$ & $100 \%$ & $100 \%$ & $100 \%$ & $100 \%$ & $100 \%$ \\
\hline M4 & & & & N/A & & & \\
\hline \multirow[t]{4}{*}{ M5 } & 1 & $30 \%$ & $10 \%$ & $10 \%$ & $30 \%$ & $10 \%$ & $10 \%$ \\
\hline & 2 & $0 \%$ & $0 \%$ & $70 \%$ & $0 \%$ & $0 \%$ & $70 \%$ \\
\hline & 3 & $0 \%$ & $0 \%$ & $0 \%$ & $0 \%$ & $0 \%$ & $0 \%$ \\
\hline & 4 & $20 \%$ & $0 \%$ & $20 \%$ & $20 \%$ & $0 \%$ & $10 \%$ \\
\hline
\end{tabular}

\subsubsection{Steps of Move 1}

Move 1 manifested differently in each degree abstracts. The first one, Step 1 which intended to argue for topic significance occurred $50 \%$ in undergraduate levels both in the Indonesian and English versions. Likewise, for graduate students in their Indonesian and English abstracts, this step also occurred with the same percentage that is $60 \%$. Meanwhile, in postgraduate abstracts, a slight difference was identified. This step occurred $80 \%$ in postgraduate Indonesian abstracts, meanwhile, it occurred $70 \%$ in English version.

Step 2 of Move 1 occurred $70 \%$ and $60 \%$ at the undergraduate level respectively. Moreover, it appeared in Indonesian and English abstracts of graduate students with the same percentage, 70\%. Meanwhile, for graduate students, this move occurred $10 \%$ higher in English than Indonesian version of abstracts. 
Step 3 of Move 1 occurred with a relatively low percentage for each education level. It appeared $0 \%$ in Indonesia version of undergraduate abstracts, however, it occurred $10 \%$ for the rest categories both in Indonesian and English version of abstracts. Thus, this step may be considered optional to be used in abstracts.

The last step was Step 4 of Move 1, the occurrence of this step across degree was relatively low. It did not appear in Indonesian undergraduate abstracts and only materialize $10 \%$ in the English version. For graduate levels, this step did not appear both in Indonesian and English abstracts. Whereas, for postgraduate students abstracts, this step occurred $10 \%$ both in Indonesian and English version.

\subsubsection{Steps of Move 3}

There were three steps in Move 3. Each step manifests different information about the methodology section. Step 1 occurred $80 \%$ in graduate and postgraduate abstracts both in Indonesian and English versions. However, for the undergraduate level, Step 1 occurred $60 \%$ in Indonesian version and $70 \%$ in English version.

For Step 2, the percentage appeared with a slight difference in Indonesian and English versions. For the undergraduate level, it occurred $80 \%$ in Indonesian and $60 \%$ in English abstracts. Meanwhile, at the graduate level, it appeared $80 \%$ and $70 \%$ in Indonesian and English versions respectively. Moreover, in Indonesian version of postgraduate abstracts, this step occurred $70 \%$ and $60 \%$ in the English version. Step 3 which describes the procedure of study appeared $100 \%$ in all education levels both in Indonesian and English versions.

\subsubsection{Steps of Move 5}

Generally, the steps of Move 5 occurred in a low percentage across education levels. Step 1 occurred $30 \%$ both in Indonesian and English versions of undergraduate abstracts. For the graduate level, it occurred $10 \%$ in both languages, and for the postgraduate level, it also occurred in the same percentage in both languages, that is $10 \%$.

Step 2 of this Move only appeared at the postgraduate level with $70 \%$. It did not occur in the other two degree levels. For Step 3, it did not appear in abstracts from any degree. Whereas, the last step of Move 5 only occurred in undergraduate and postgraduate abstracts.

These findings demonstrate that the three degrees of education manifest a quite similar preference of steps in their abstracts, except the steps of Move 5 which mostly appeared in postgraduate abstracts. Steps of Move 2Purpose, Move 3-Method, and Move 4-Findings are more likely to be included in the abstracts than steps of Move 1 and Move 5. The number of occurrences of Step 1-describing participants and Step 3-describing procedure in the Method move was similar (Kurniawan et al., 2019). Step 3 of Move 3 and Step 2 of Move 4 are the most used steps across education levels. It is in line with Gustina's (2020) finding that Move 3 Step 3 is one of the most manifested steps in abstracts. It may be indicated that students tend to emphasize the procedure and findings of research in their abstracts. Meanwhile, steps of Move 5 are hardly found in the abstracts, except postgraduate abstracts. It may be because postgraduate students are more aware of rhetorical convention of abstracts. Thus, it is indicated that differences in education level may affect step realization in abstracts. Furthermore, this study demonstrates that there are only some minor differences in move and step preferences between English and Indonesian abstracts. It may occur because the data were parallel abstracts.

\section{CONCLUSION}

This study has addressed two research questions: How are the rhetorical move patterns of the Indonesian English abstracts realized across education levels? How is the step pattern of the Indonesian English abstracts realized across education levels? The findings demonstrate that all of the moves and their steps were included in the three levels of education abstracts. However, some differences between the rhetorical moves and steps used across education levels also occurred. Undergraduate and graduate students tend to emphasize Method, Findings, and Purpose of their research in the abstracts and put less attention on the Conclusion. Meanwhile, postgraduate students tend to give extensive information in their abstract including Introduction and Conclusion. As a result, postgraduate abstracts were more likely to manifest the five moves. Regarding the step realization, the three levels of education manifest quite similar preferences of steps in their abstracts, except the steps of Move 5 which mostly appeared in postgraduate abstracts. Furthermore, this study demonstrates that there are only some minor differences in move and step preferences between English and Indonesian abstracts. It may occur because the abstracts used in this study were parallel. This study concludes that differences in education level may affect move and step realization in thesis or dissertation abstracts.

For future research, authors can explore another element of the abstracts, such as linguistic or translation aspects of the abstracts. In addition, the authors can conclude that the findings of this study may be used by 
students from different levels of education. It is recommended for students to include more types of Move and Step in their abstracts. Besides, it is also recommended for universities to provide a template about making a good abstract for their students. By understanding the use of rhetorical move, hopefully, students can make a good abstract for their thesis and/or dissertation.

\section{ACKNOWLEDGMENTS}

This study was supported by a grant from the Research and Community Service Unit, Universitas Pendidikan Indonesia. The authors would like to express appreciation for all the support provided.

\section{REFERENCES}

Arono \& Arsyad, S. (2019). The Effect of genre-based mentoring on rhetorical quality of research article drafts by Indonesian lecturers in social sciences and humanities. International Journal of Instruction, 12(3), 35-50. https://doi.org/10.29333/iji.2019.1233a

El-Dakhs, D. A. S. (2020). Are Arabic and English Research article abstracts different? Rhetorical Structure \& Interaction in focus. The Asian ESP Journal, 16(5.1), 6-32.

Gustina, A. R. (2020). Move Analysis Of Undergraduate Theses And undergarduate students' published research articles abstracts [Undergraduate thesis]. Universitas Pendidikan Indonesia, Bandung, Indonesia. Retrieved from http://repository.upi.edu/53620

Hyland, K. (2000). Disciplinary discourses: Social Interactions in academic writing. Ann Arbor, USA: The University of Michigan Press.

Kurniawan, E., Lubis, A.H., Suherdi, D., \& Danuwijaya, A.A. (2019). Rhetorical Organization of applied linguistics abstracts: Does scopus journal quartile matter?" GEMA Online Journal of Language Studies, 19(4), 184-202. https://doi.org/ 10.17576/gema-2019-1904-10

Li, X. (2020). Mediating cross-cultural differences in research article rhetorical moves in academic translation: A pilot corpus-based study of abstracts. Lingua, 238, 102795. https://doi.org/10.1016/j.lingua.2020.102795

Male, H. (2018). A Structural move analysis of abstracts in undergraduate theses: A Case study at Universitas Kristen Indonesia. KnE Social
Sciences, $\quad 3(9), \quad 284$. https://doi.org/10.18502/kss.v3i9.2690

Swales, J. M. (1990). Genre analysis: English in academic and research settings. Cambridge, UK: Cambridge University Press.

Tamela, E. (2020). Move structure analysis on research article abstracts in national and international SCOPUS indexed journals. Saeeaw \& Tangkiengsirisin 434: 12-17.

Tankó, G. (2017). Literary research article abstracts: An analysis of rhetorical moves and their linguistic realizations. Journal of English for Academic Purposes, 27, 42-55. https://doi.org/10.1016/j.jeap.2017.04.003 